\title{
CLINICAL USES OF 2,3-DIMERCAPTOPROPANOL (BAL). III. STUDIES ON THE TOXICITY OF BAL ON PERCUTANEOUS AND PARENTERAL ADMINISTRATION ${ }^{1}$
}

\author{
By MARION B. SULZBERGER, RUDOLF L. BAER, AND ABRAM KANOF
}

(From Cornell University Medical College, New York City)

(Received for publication February 5, 1946)

Ointments and vehicles containing BAL may, on occasion, have to be used over extensive skin areas, and also repeatedly, within relatively short periods of time. For this reason it was essential to ascertain the possible systemic toxic effects of BAL on repeated application to extensive skin areas in man. Moreover, before the parenteral administration of BAL could be adopted as a method for treating certain metallic poisonings, it was imperative to ascertain the toxicity of BAL preparations when administered parenterally in human subjects.

The following are among the important findings which form the background of the present studies. Early experiments in laboratory animals had demonstrated that the external application of BAL to the skin can produce systemic toxic manifestations and even lethal effects (1 to 4). With 1 early sample of BAL, doses of $600 \mathrm{mgm}$. per $\mathrm{kgm}$. killed about $1 / 2$ the mice when applied externally. It has been shown, however, that early lots of BAL were considerably more toxic than the standard product of later manufacture.

Also, there was evidence that significant quantities of BAL penetrate the grossly normal human skin quite rapidly when BAL is applied, either undiluted or in various vehicles. This is shown by the almost immediate whealing and erythema produced, and by certain systemic effects which have been observed following external application. The latter include the benefits produced on arsenical dermatitis in skin areas distant from the actual sites of application (5), and the occasional malaise, nausea, etc. seen during the course of experimental application of BAL to the skin.

Thus Stocken and Thompson (1) applied 0.5 ml., and later $1 \mathrm{ml}$., of undiluted British BAL to

1 The work described in this paper was done under a conitract, recommended by the Committee on Medical Research, between the Office of Scientific Research and Development and Cornell Medical College. the arm of a normal test subject. With both doses there followed an evanescent "scarlatiniform rash" on the area of exposure; and with the larger dose there were slight conjunctivitis, lachrymation and salivation.

\section{STUDIES ON THE TOXICITY OF BAL ON PERCUTANEOUS ADMINISTRATION ${ }^{2}$ \\ Method}

In a first experiment, 5 generally healthy, young, white, male subjects received 3 grams of BAL 10 per cent in $\mathrm{K}-\mathrm{Y}$ jelly (in 3 subjects), and BAL 10 per cent in petrolatum (in 2 subjects) rubbed into the skin of the arms and forearms. Transitory erythema and whealing were produced in several of the subjects, but no apparent systemic ill effects were observed.

Five generally healthy, young, white, male subjects were selected for a second experiment. General physical examinations, complete blood counts, urine analyses, blood pressure and temperature measurements were carried out on these subjects for 24 hours preceding the application of BAL. All findings were within normal ranges. Each subject received 1 ounce of BAL 5 per cent in $K-Y$ jelly rubbed in vigorously over the neck, entire back, shoulders, chest, abdomen and upper arms. The amount of BAL applied was 1.5 grams. None of the applied material was deliberately removed.

\section{Results}

Varying degrees of local skin reactions were noted at the sites of inunction, ranging from severe generalized whealing over the entire area of application in one subject to no visible skin reaction whatsoever. Two other subjects showed moderate degrees of evanescent urticaria at the sites of application. In the subject with severe whealing, the lesions subsided gradually during the 20 hours following inunction, and at 36 hours there was only slight erythema to be seen.

One of the subjects, about 20 minutes after the inunction, complained of feeling faint and dizzy and had to lie down. While he did not lose consciousness entirely, he appeared like a person in

2 This experiment was carried out in collaboration with Dr. Harry Katz. 
a faint. The pulse was scarcely perceptible, but when it could be counted was regular, and not accelerated. There was extreme pallor and the skin was moist. There were no convulsive phenomena, but as precaution $11 / 2$ grains (about 0.1 gram) of phenobarbital were given 40 minutes after the inunction. Recovery was gradual, but the subject appeared well and was smoking a cigarette within $1 \frac{1}{2}$ hours after inunction.

This subject gave a history of previous fainting spells and it was not possible to ascertain to what degree, if any, the shock-like condition was attributable to psychogenic factors. The close atmosphere and the strong, and to many people disagreeable, smell of BAL in the room in which the experiment was performed, may also have been factors in producing the reaction in this subject.

General physical examinations, blood counts, urine analyses and blood pressure and temperature measurements were carried out in all subjects at regular intervals during the 48 hours after the inunctions. There were no abnormal findings and no changes which could be attributed to the $\mathrm{BAL}$ inunctions in any of the subjects.

\section{STUDIES ON THE TOXICITY OF BAL ON} INTRAMUSCULAR ADMINISTRATION ${ }^{3}$

\section{Method}

1. Subjects: These experiments were carried out on 34 healthy male volunteers ranging from 17 to 29 years in age, and from 55.3 to $86.0 \mathrm{kgm}$. in weight. The average weight was close to $70 \mathrm{kgm}$.

2. Material: A solution containing American Reference Standard BAL 10 per cent, benzyl benzoate 20 per cent in peanut oil (prepared and filled in ampules by Hynson, Westcott and Dunning Inc.).

3. Mode of Administration: By deep intramuscular injection, alternately in the upper outer quadrant of the right and left gluteal areas. A new site was chosen for each injection.

4. Dosage: Three series of tests were performed, each one utilizing a different dosage and/or time schedule. These 3 series were as follows:

Series $I$

5 subjects, 4 injections (one every 4 hours) as follows:

(1) $1.5 \mathrm{ml}$. (150 mgm. BAL) at 8 a.m.

(2) $2.0 \mathrm{ml}$ ( (200 mgm. BAL) at 12 noon

(3) $2.8 \mathrm{ml}$. (280 mgm. BAL) at 4 p.m.

(4) $3.0 \mathrm{ml}$. ( $300 \mathrm{mgm} . \mathrm{BAL}$ ) at $8 \mathrm{p.m}$.

8 These studies were carried out under a program directed by Dr. Harry Eagle and with the cooperation of Drs. McKeen Cattell and Harry Gold.
Series II

24 subjects, 8 . injections (on 2 successive days) as follows:

1st day (1) $1.5 \mathrm{ml}$. (150 mgm. BAL) at 8 a.m.

(2) $2.0 \mathrm{ml}$. (200 mgm. BAL) at 12 noon

(3) $2.5 \mathrm{ml}$. (250 mgm. BAL) at 4 p.m.

(4) $3.0 \mathrm{ml}$. (300 mgm. BAL) at $8 \mathrm{p.m}$.

2nd day (5) $3.5 \mathrm{ml}$. (350 mgm. BAL) at 8 a.m.

(6) $3.5 \mathrm{ml}$. (350 mgm. BAL) at 12 noon

(7) $3.5 \mathrm{ml} .(350 \mathrm{mgm}$. BAL) at $4 \mathrm{p} . \mathrm{m}$.

(8) $3.5 \mathrm{ml}$. (350 mgm. BAL) at $8 \mathrm{p.m}$.

In Series I and II the highest single dose was $5.5 \mathrm{mgm}$. per $\mathrm{kgm}$. of body weight. The highest total dose in 12 hours was $22 \mathrm{mgm}$. per $\mathrm{kgm}$. On the second day in Series II the average single dose was $5 \mathrm{mgm}$. per $\mathrm{kgm}$., and average total dose in 12 hours was $20 \mathrm{mgm}$. per $\mathrm{kgm}$.

Series III

5 subjects, 4 injections as follows:

(1) $3.5 \mathrm{ml}$. (350 mgm. BAL) at 9:30 a.m.

(2) $3.5 \mathrm{ml}$. (350 mgm. BAL) at $11: 30$ a.m.

(3) $3.5 \mathrm{ml}$. (350 mgm. BAL) at 3:30 p.m.

(4) $3.5 \mathrm{ml}$. (350 mgm: BAL) at 7:30 p.m.

In Series III the highest single dose was $6.3 \mathrm{mgm}$. per $\mathrm{kgm}$. of body weight. The highest total dose in 10 hours was $25.3 \mathrm{mgm}$. per $\mathrm{kgm}$., and in 2 hours $12.7 \mathrm{mgm}$. per $\mathrm{kgm}$. The average total dose in 10 hours was $20.8 \mathrm{mgm}$. per $\mathrm{kgm}$., and in 2 hours $10.4 \mathrm{mgm}$. per $\mathrm{kgm}$.

5. Examination: In Series I, II and III the following examinations were carried out:

(a) General physical examination.

(b) Measurements of pulse rate, respiration rate and blood pressure before and after injections or as required.

(c) Observations of objective and subjective changes in general.

In Series I and II the following additional examinations were carried out:

(d) Measurement of temperature.

(e) Complete urinalysis before and after each day's course of injections.

(f) Complete blood counts before and after course of injections.

(g) $\mathrm{CO}_{2}$ combining power ${ }^{4}$ and levels of reducing substances of blood (Folin-Wu method) before and after each day's course of injections.

In 12 subjects of Series II the following additional examinations were carried out:

(h) Icteric index of blood and urobilin tests of urine after the course of injections.

4 Carried out by Miss A. Paterno, Dept. of Pharmacology, Cornell University Medical College. 


\section{Local effects}

\section{Results}

Beginning a few minutes after the injection, there were varying degrees of pain in the gluteal area around injection sites and some radiating pain and stiffness of the leg. The pain and stiffness were also variable in degree, sometimes moderately severe and persisting through the following 24 hours. There was slight tenderness of most injection sites at 24 hours. No severe local reactions, such as redness, swelling, infiltration or abscess formation, were noted.

\section{General signs and symptoms}

The series of injections were completed as planned in all volunteers except subject H. V. A. In this subject the injections were discontinued after the second injection on the second day because of the somewhat threatening character of the reactions. A few subjects complained of slight headache, slight nausea and slight burning of the mouth at even the lowest dosage. Unequivocal complaints generally began at the dose of $250 \mathrm{mgm}$. of BAL per injection, i.e. at a dose of about $3.6 \mathrm{mgm}$. per $\mathrm{kgm}$. The significant manifestations set in within a few minutes after the respective injection, usually reached a maximum between 10 and 30 minutes after injection, and then generally subsided rather rapidly. The effects listed in approximate order of frequency were as follows:

(1) Nausea (and, in 11 instances, vomiting)

(2) Headache

(3) Burning sensation of lips, mouth, throat, constricted feeling and sometimes pain of throat, chest and/or hands

(4) Conjunctivitis, tearing, rhinorrhea and salivation

(5) Tingling of the hands

(6) Burning sensation of penis

(7) Sweating of forehead, hands, etc.

(8) Abdominal pain.

In Series I and II the symptoms, when they appeared after a certain dose, for example, 250 mgm. of BAL, usually reappeared at the subsequent injections, but there was no general increase in the severity of the manifestations on successive injections, and little or no evidence of cumulation. The one possible exception is the case of $\mathrm{H}$. V. A. described in detail below. In some cases there was perhaps a suggestion of increasing tolerance, later injections of the same dose sometimes producing fewer complaints than preceding ones.

However, in Series III distinct evidence of cumulative toxicity could be observed. In all 5 subjects the second injection, i.e. the one given within 2 hours of the first dose, produced signs and symptoms of much greater intensity than any of the other administrations. This cumulative effect was no longer evident at the third injection 4 hours later, nor at the fourth injection given after another 4-hour interval. Thus the first, third and fourth injections of Series III produced reactions of the same degree as those observed in Series I and II after doses of $350 \mathrm{mgm}$., while the second injection of $350 \mathrm{mgm}$. in Series III apparently produced additive effects with the BAL remaining from the first injection, and resulting in the following more severe toxic sequelae:

(a) Burning sensation of lips, mouth, throat ( 5 out of 5 subjects)

(b) Conjunctivitis, tearing, rhinorrhea, salivation (5 out of 5 subjects)

(c) Abdominal pain, moderate to very severe (4 out of 5 subjects)

(d) Headache (3 out of 5 subjects)

(e) Constricted feeling, burning pain of throat and chest (2 out of 5 subjects)

(f) Tremors and shakiness (2 out of 5 subjects)

(g) Nausea (1 out of 5 subjects)

(h) Lower back pain (1 out of 5 subjects)

(i) Uncontrollable laughing (1 out of 5 subjects).

\section{Laboratory findings}

Urine: One subject who had a trace of albumin before the first injection developed 2 plus albumin and a few casts at the end of the second day of injections (subject H. V. A.-see below).

Eleven subjects developed reducing substances in the urine during the series of injections (Benedict's Test). In 6 of these, there were only traces of reducing substances, while in 5 , reactions were 1 to 2 plus.

All other urinary findings were normal throughout.

Blood: Blood counts showed no significant abnormalities.

The levels of reducing substances in the blood were all within normal limits. 
There was no evidence that the injection produced a reduction in the $\mathrm{CO}_{2}$ combining power.

The icteric indices measured were all within normal range.

\section{Clinical findings}

Temperatures (oral) : These were all within the normal range.

Pulse rates: There was slight transitory acceleration of the pulse rate in 2 subjects following the injections; and in one instance the pulse dropped to 48 a few minutes after the injection (this individual also presented cold sweating of hands and forehead).

Respiration rates: In general, the respirations tended to increase slightly in frequency within 15 to 20 minutes after the injections (maximum was 26 per minute in one subject).

Blood pressures: All subjects had normal blood pressure at the beginning of the tests. There was a distinct tendency for both the systolic and disastolic pressures to rise slightly within 30 to 40 minutes after the injections. How uniform this reaction was, is not certain since the blood pressure readings in the first 17 subjects were not taken at the 30- to 40-minute period. In Series $I$ and II, the blood pressures tended to return to normal within 60 to 90 minutes after the injections. The one exception was H. V. A., whose pressure was elevated for over 2 hours. In Series III the blood pressures were all within the normal range within 3 hours after the BAL injection. Among those subjects in whom the blood pressure was taken at 30 to 40 minutes, 14 of 17 subjects showed significant elevations.

\section{Blood Pressures}

\begin{tabular}{cc}
\hline \hline $\begin{array}{c}\text { Before start } \\
\text { of experiment }\end{array}$ & $\begin{array}{c}\text { Maximum } \\
\text { observed }\end{array}$ \\
\hline $120 / 70$ & $144 / 94$ \\
$120 / 76$ & $164 / 106$ \\
$110 / 70$ & $164 / 110$ \\
$104 / 80$ & $136 / 90$ \\
$98 / 60$ & $144 / 90$ \\
$130 / 80$ & $150 / 86$ \\
$130 / 80$ & $150 / 112$ \\
$120 / 80$ & $144 / 104$ \\
$126 / 84$ & $220 / 140$ \\
$110 / 60$ & $146 / 100$ \\
$124 / 174$ & $200 / 120$ \\
$130 / 74$ & $144 / 92$ \\
$126 / 80$ & $150 / 104$ \\
$118 / 70$ & $146 / 96$ \\
\hline
\end{tabular}

Tests for systemic sensitization to $B A L$

Fifteen of the original 29 subjects were available for repetition of intramuscular injections of BAL solution at 15 to 27 days after the last previous intramuscular injection of BAL 10 per cent solution. These subjects each received readministrations of $\mathrm{BAL}$ as follows : $1.0 \mathrm{ml}$. of $\mathrm{BAL} 10$ per cent (100 mgm. BAL) in benzyl benzoatepeanut oil solution, deep intramuscularly, followed
2 to $21 / 2$ hours later by an injection of $3.5 \mathrm{ml}$. (350 mgm. BAL).

The examinations carried out at the time of readministration included general physical examination, measurements of pulse rate, respiration rate and blood pressure before and after injections or as required, and observation of objective and subjective changes in general.

There were no signs or symptoms of systemic hypersensitivity or sensitization. The injections were tolerated in a manner analogous to that exhibited by these same subjects at the time they had received their first injections of the equivalent amounts 15 to 27 days previously.

It is perhaps noteworthy that among the 15 subjects reinjected, there were 4 who had acquired skin sensitization as evidenced by the positive patch tests to BAL (6). As stated, these subjects showed no evidence of systemic hypersensitivity. Moreover in no instance did the intramuscular reinjection of $460 \mathrm{mgm}$. of BAL produce a cutaneous reaction or dermatitis in these patch-test positive subjects.

\section{COMMENT .}

The studies on percutaneous absorption of BAL indicate that under the conditions of the studies presented, no significant systemic toxic manifestations occurred from the topical application of BAL preparations. The single exception was the subject who fainted after application of 1 ounce of BAL 10 per cent in $\mathrm{K}-\mathrm{Y}$ jelly, and who had a previous history of occasional fainting spells. It appears very possible that the faint was purely psychogenic. The strong fumes of BAL in the room may have had something to do with the reaction. There were no convulsive phenomena, which are considered characteristic of BAL intoxication.

The varying degrees of transitory local urticarial and erythematous reactions which were noted in many of the inuncted subjects cannot be considered as pathologic or abnormal responses. This form of reaction corresponds to that seen after inunction of other primary urticariogenic agents, such as pilocarpine, atropine, histamine, codeine, etc.

The studies on toxicity of BAL after intramuscular injection indicate that some transitory 
toxic manifestations do occur at doses of approximately 3 to $4 \mathrm{mgm}$. of BAL per $\mathrm{kgm}$. Even 4 doses, each of about $5 \mathrm{mgm}$. of BAL per $\mathrm{kgm}$., administered at 4-hour intervals, produced no severe or lasting damage in the average normal individual; with the $5 \mathrm{mgm}$. per $\mathrm{kgm}$. dosage given 4 times at 4-hour intervals, there was no evidence of cumulative toxicity. However, when the second dose of $5 \mathrm{mgm}$. per $\mathrm{kgm}$. was given after a 2-hour, instead of a 4-hour interval, definite signs of cumulative, although not conspicuously dangerous, toxicity were noted.

Based on these and coordinated studies, the dosage of $4 \mathrm{mgm}$. of BAL per $\mathrm{kgm}$. given in 4 doses at 4-hour intervals, was adopted for the treatment of systemic arsenic poisoning (7). This dosage schedule appears well within the safe range established in our studies.

In considering our results and before drawing practical conclusions from them, it should be pointed out that all our studies described in the present report were conducted on subjects who were not suffering from arsenical or other metallic poisoning. When BAL is used under practical circumstances, it will almost always be in individuals who are suffering from systemic poisoning due to arsenic or other metals. Therefore, the possibility must be considered that tolerance to BAL may be affected by the presence or absence of arsenical or other metallic poisoning.

\section{SUMMARY AND CONCLUSIONS}

1. Approximately 0.3 gram of BAL applied to the skin in the form of BAL 10 per cent in $\mathrm{K}-\mathrm{Y}$ jelly, or BAL 10 per cent in petrolatum, produced no signs or symptoms in 5 healthy, white, male subjects except for transitory local erythema, whealing, and itching at the site of application.

2. Approximately 1.7 grams of BAL applied to large. areas of the skin in the form of a 5 per cent concentration in $\mathrm{K}-\mathrm{Y}$ jelly produced no convulsive phenomena, blood changes, kidney or other damage, and no other forms of systemic poisoning in any of 5 healthy young male subjects.

However, one subject became faint within 20 minutes after the application. The possibility that this fainting spell may have been caused by psychogenic rather than toxic factors is suggested by a previous history of fainting spells in this subject.
There were various degrees of local whealing, ranging from scarcely visible isolated evanescent wheals in some subjects, to severe generalized whealing of all the areas receiving the inunction in one subject. In this last subject the wheals persisted for about 20 hours. The local skin effects were not incapacitating in any of the 5 subjects.

3. A solution containing 10 per cent BAL and 20 per cent benzyl benzoate in peanut oil was injected according to various dosage schedules in a total of 34 human volunteers. There was considerable variation in the individual response, but in general, toxic manifestations appeared at a dose of approximately 3.6 to $5.5 \mathrm{mgm}$. per $\mathrm{kgm}$. These manifestations included nausea, vomiting, headache, burning sensation of lips, mouth and throat, feeling of constriction and sometimes pain in throat and chest, burning and tingling of extremities, conjunctivitis, tearing, rhinorrhea, salivation, sweating of forhead and hands, abdominal pain, and general agitation. Local pain at the site of injection and muscle spasm of the leg were also quite common. Perhaps the most significant finding was elevation of systolic and diastolic blood pressure within about $1 / 2$ hour after the injection.

4. Except for 1 subject in whom some of the ill effects persisted for over 24 hours, the subjects had returned to normal within 45 minutes to 2 hours after the injections. No regular cumulative effects were noted when 4 doses of approximately $5 \mathrm{mgm}$. per $\mathrm{kgm}$. were given in 4 successive injections 4 hours apart. However, when the first 2 doses were given with an interval of only 2 hours, distinct cumulative toxicity was observed.

5. Reinjections of a total average dose of 6.2 mgm. BAL per $\mathrm{kgm}$. administered 15 to 27 days after the last previous injection elicited no signs of systemic sensitization.

6. Attention is called to the fact that these studies were carried out in volunteers who were not suffering from arsenical or other metallic poisoning. The presence or absence of such poisoning may or may not be a factor in determining the tolerance of BAL.

7. It is concluded that topical application of BAL preparations, at least within the dosages employed in our studies, is a safe procedure. It is furthermore concluded that while toxic manifestations 
occur after the intramuscular administration of BAL, 4 doses each of about $5 \mathrm{mgm}$. of BAL per kgm., administered at 4-hour intervals, will produce no severe or lasting damage in the average normal individual. When the first 2 doses are given only 2 , instead of 4 hours, apart, cumulation occurs, and more severe symptoms can be expected, although these too are transitory, and are followed by relatively prompt recovery in normal individuals.

\section{BIBLIOGRAPHY}

1. Peters, R. A., Stocken, L. A., and Thompson, R. H. S., British Anti-Lewisite (BAL). Nature, 1945, 156, 616.
2. Waters, L. L., and Stock, C. C., BAL (British AntiLewisite). Science, 1945, 102, 601.

3. Calder, R. M., 1941, Personal communication.

4. Modell, W., Gold, H., and Cattell, M., Pharmacologic observations on BAL by intramuscular injection in man. J. Clin. Invest., 1946, 25, 480.

5. Longcope, W. T., Luetscher, J. A., Jr., Wintrobe, M. M., and Jager, V., The treatment of arsenical dermatitis with preparations of BAL. J. Clin. Invest., 1946, 25, 528.

6. Sulzberger, M. B., Baer, R. L., and Kanof, A., Skin sensitization to BAL. J. Clin. Invest., 1946, 25, 488.

7. Eagle, H., and Magnuson, H. J., The systemic treatment of 227 cases of arsenic poisoning (encephalitis, dermatitis, blood dyscrasias, jaundice, fever) with 2,3-dimercaptopropanol (BAL). Am. J. Syph. In press. 